\title{
Causes of False Negative Bedside Head Impulse Test
}

\author{
Dae-Young Kim ${ }^{1}$, Yoon-Gi Choi ${ }^{1}$, Tae-Suk Kyung ${ }^{1}$, Jun-Ha Hwang ${ }^{1}$, \\ Hyun Ji Kim ${ }^{1}$, Seung Chul Lee ${ }^{2}$, and Kyu-Sung Kim ${ }^{1}$ \\ ${ }^{I}$ Department of Otorhinolaryngology-Head and Neck Surgery, Inha University College of Medicine, Incheon; and ${ }^{2}$ Soree Ear Clinic, \\ Seoul, Korea
}

\author{
나안 두부충동검사에서 위음성의 원인분석 \\ 김대영 ${ }^{1} \cdot$ 최윤기 ${ }^{1} \cdot$ 경태석 ${ }^{1} \cdot$ 황준하 $^{1} \cdot$ 김현지 $^{1} \cdot$ 이승철 ${ }^{2} \cdot$ 김규성 $^{1}$ \\ 인하대학교 의과대학 이비인후-두경부외과학교실, ${ }^{1}$ 소리이비인후과 ${ }^{2}$
}

\author{
Received August 5, 2016 \\ Revised November 22, 2016 \\ Accepted November 29, 2016 \\ Address for correspondence \\ Kyu-Sung Kim, MD \\ Department of Otorhinolaryngology- \\ Head and Neck Surgery, \\ Inha University College of Medicine, \\ 27 Inhang-ro, Jung-gu, \\ Incheon 22332, Korea \\ Tel $+82-32-890-3620$ \\ Fax $+82-32-890-3580$ \\ E-mail Stedman@inha.ac.kr
}

\begin{abstract}
Background and Objectives The bedside head impulse test (bHIT) in bare eyes often overlooks possible vestibular losses by missing the corrective saccade. This is why it is necessary to compare bHIT against video head impulse test (vHIT), which is more accurate in identifying vestibular losses than the bedside test.

Subjects and Method A total of 51 vHIT positive ears underwent the study, and out of those, 47 were diagnosed with dizziness. bHIT and vHIT were performed for patients, and the occurrence rate of overt saccade (OS) was calculated.

Results Among the 51 vHIT positive ears, 33 (64.7\%) were bHIT positive ears and 18 ears $(35.3 \%)$ were bHIT negative. Patterns of positive vHIT were classified as A: no corrective saccade, B: covert saccade (CS) only, C: OS only, and D: CS with OS (CS+OS), which were 45 out of 51 ears $(88 \%)$. The occurrence rate of OS was higher in the bHIT positive group than in the bHIT negative group ( $p=0.05)$, and higher in the CS negative group (CS-) than in the CS positive group $(\mathrm{CS}+)(p<0.001)$.

Conclusion Possible causes of false negative results of bHIT are seen as following: the absence of corrective (covert and overt) saccade, the occurrence of CS only, and missing the OS during the bHIT (probably due to low occurrence rate of OS). The occurrence of CS should be considered as an important factor in false negative bHIT when lowering the occurrence rate of OS. Korean J Otorhinolaryngol-Head Neck Surg 2017;60(3):107-11
\end{abstract}

\section{서 론}

나안 두부충동검사(bedside head impulse test)는 말초성 전정기능장애를 확인하기 위한 검사로서 침상에서 할 수 있 는 매우 간단하고 유용한 검사로 이전 연구에서는 나안으로 시행한 두부충동검사를 온도안진검사와 비교하였을 때 $56 \%$ 의 민감도와 $90 \%$ 의 특이도를 가진다고 보고하였다. ${ }^{1)}$ 그러나 나안 두부충동검사에서는 교정성 홱보기(corrective saccade) 를 놓쳐 전정기능장애를 간과하게 되기도 하며 냉온교대 온 도안진검사와 주파수의 범위도 달라 이로 인해 발생하는 위
음성 결과들에 대해서 아직 진행된 연구가 많지 않다.

비디오 두부충동검사(video head impulse test)는 나안 두부 충동검사와 같은 주파수에서 전정기능장애를 더욱 정확히 확인할 수 있도록 개발되었고, 현재 이 둘을 비교하는 연구들 이 진행되고 있다. 이전 연구에서 나안 두부충동검사는 중등 도의 민감도를 가지며 전정안반사(vestibulo-ocular reflex)의 감소를 배제할 수 있는 유용한 검사법이지만 경미한 정도의 전정장애는 놓치기 쉬우며 이를 위해 비디오 두부충동검사 의 필요성이 주장된 바 있다. ${ }^{2)}$ 본 연구에서는 비디오 두부충 동검사를 현재 대부분의 일차 진료 시에 시행되고 있는 나안 
두부충동검사와 비교하여 둘 사이의 일치도를 분석하고 나 안 두부충동검사에서 위음성이 나오는 원인을 고찰함으로써 어지럼의 감별에 도움이 될 수 있는 방법을 찾아보고자 한다.

\section{대상 및 방법}

\section{대 상}

2013년 1월부터 12월까지 어지럼을 주소로 내원한 47명의 환자 중 비디오 두부충동검사에서 양성소견을 보인 51귀를 대상으로 연구하였다. 연구 대상에서 퇴행성 질환 등의 원인 으로 경부 운동의 제한이 있거나 안구 운동의 장애, 시야 및 시력의 심한 결손 등으로 두부충동검사를 시행할 수 없는 환 자들은 배제되었다.

\section{방 법}

비디오 두부충동검사는 국내에서 상용화되어 사용 중인 비디오 두부충동검사 기기(ICS impulse ${ }^{\circledR}$; GN Otometrics, Taastrup, Denmark)를 이용하여 수평면에 대해 좌우 각각 20회씩 무작위로 시행하였다. 이전 연구에서 두부충동검사 에서 이득의 정상 범위 최저값은 $95 \%$ 신뢰구간(mean士 2SD)을 통해 0.68 0.84로 보고되었으며 ${ }^{3)}$ 본 연구에서도 비 디오 두부충동검사의 양성을 교정성 홱보기의 유무와 상관 없이 전정안반사의 이득이 0.8 이하인 경우로 정의하였다. 또 한 각각의 검사마다 발생한 교정성 홱보기의 수를 두부충동 이 종료되기 전에 일어나는 covert 홱보기와 두부충동이 종 료된 이후에 나타나는 overt 홱보기로 분류하여 확인하였다

(Fig. 1).

비디오 두부충동검사의 결과를 나안 두부충동검사의 결과 와 비교하기 위해 overt 홱보기의 발생률을 계산하였으며 이 는 한 귀에서 overt 홱보기가 발생한 횟수를 총 시행한 검사 의 횟수로 나눈 것으로 정의하였다.

Overt 홱보기 발생률(\%)=(overt 홱보기 횟수/총 검사 횟 수) $\times 100$
나안 두부충동검사는 $1 \mathrm{~m}$ 떨어진 목표를 응시하게 한 상 태에서 수평면으로 오른쪽, 왼쪽 각각 5 10회씩 무작위로 시 행하였으며 정확한 확인을 위해 비디오 두부충동검사 시에 이용한 고글을 착용하게 한 뒤 검사를 시행하고 그 영상을 기록하여 나안으로 확인 후 교정성 핵보기가 확인된 귀에 대 해 양성으로 판정하였다.

결과의 분석을 위해 Mann-Whitney U test 등의 통계학적 방법을 이용하였으며 $p$ 값이 0.05 이하인 경우를 통계학적으 로 유의미한 것으로 정의하였다.

\section{결 과}

\section{대상 분석}

연구에 포함된 47명의 대상 인원 중 남자는 25 명, 여자는 22명이었으며 연령은 16세부터 90세까지 다양하였으며 연령 은 평균 54세(16 90)였다.

\section{비디오 두부충동검사의 결과}

시행한 비디오 두부충동검사의 결과를 크게 네 가지 형태 로 분류하였다. $\mathrm{A}$; 교정성 홱보기가 없는 경우, $\mathrm{B}$; covert 홱 보기만 보인 경우, $\mathrm{C}$; overt 홱보기만 보인 경우, $\mathrm{D}$; covert와 overt 홱보기 모두가 보인 경우. 결과에서는 A형이 2귀(4\%), $\mathrm{B}$ 형이 1귀(2\%), C형이 3귀(6\%)에서 관찰되었으며, 나머지 45 귀(88\%)는 D형에 해당되었다(Fig. 2).

\section{나안 두부충동검사의 정확도}

비디오 두부충동검사에서 양성을 보인 51귀를 대상으로 나 안 두부충동검사를 시행한 결과 33 귀(64.7\%)에서 양성소견을 보였고 18귀(35.3\%)에서 음성소견을 보였다(Fig. 3).

\section{비디오 두부충동검사와 나안 두부충동검사의 관계}

$\mathrm{A}$ 형의 경우 나안 두부충동검사 음성에서만 2 귀 관찰되었으 며 $\mathrm{B}$ 형의 경우도 나안 두부충동검사 음성인 군에서만 1 귀 관

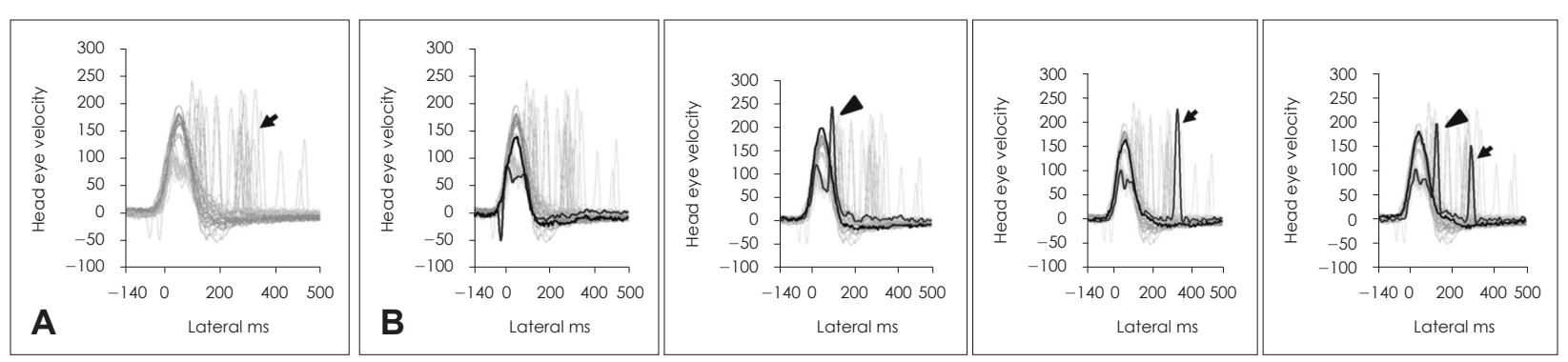

Fig. 1. Head and eye velocity recordings of video head impulse test. Cumulated recordings from repeated tests about 20 times (A). 4 types of single test recording. Each single test was recorded as a line with medium grey color (B) (arrowhead: covert saccade, arrow: overt saccade). 

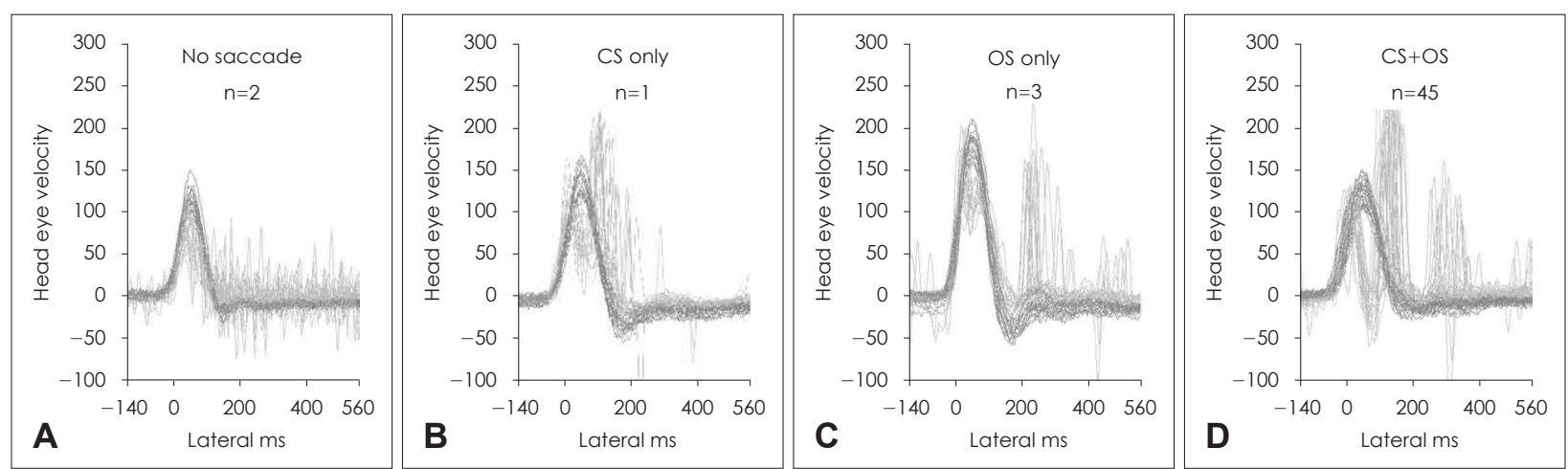

Fig. 2. Patterns of positive vHIT. Total, $n=51$. Without CS (A). CS only (B). OS only (C). CS and OS (D). CS: covert saccade, OS: overt saccade, vHIT: video head impulse test.

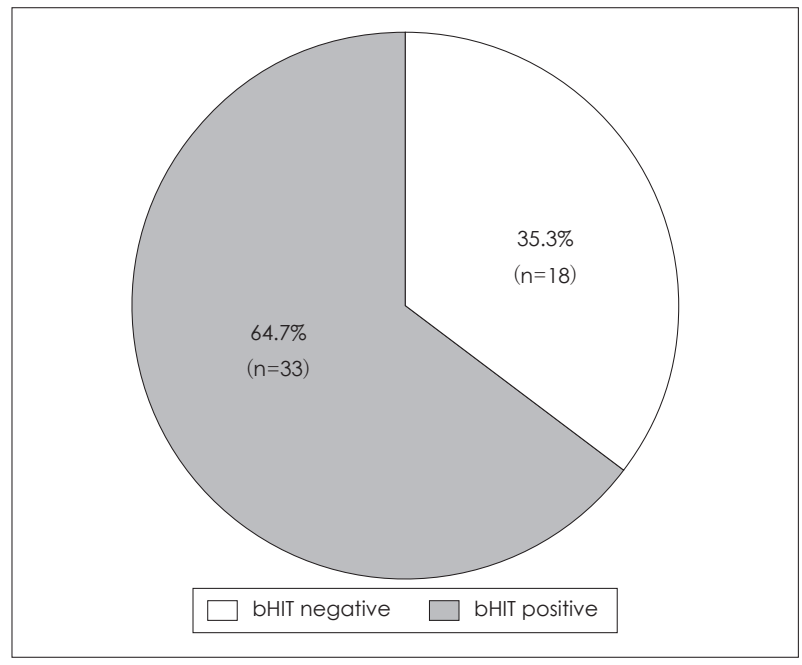

Fig. 3. Results of bHIT in vHIT positive ears. bHIT: bedside head impulse test, VHIT: video head impulse test.

찰되었다. Overt 핵보기만 관찰되는 유형인 C형은 나안 두부 충동검사 양성인 군에서만 3 귀 관찰되었으며 $\mathrm{D}$ 형에서는 나안 두부충동검사 음성 15 귀, 양성 30귀로 관찰되었다(Fig. 4).

\section{나안 두부충동검사 결과와 overt 홱보기의 관계}

나안 두부충동검사 양성군에서 overt 홱보기의 발생률은 $82.7 \pm 18.1 \%$ 로 음성군의 overt 홱보기 발생률 $37.0 \pm 26.1 \%$ 에 비 해 통계적으로 유의미한 차이를 보였다. 각 군의 발생률 차이는 Mann-Whitney U test를 통해 분석하였다( $p=0.05)$ (Fig. 5).

\section{Covert 홱보기와 overt 홱보기의 관계}

Covert 핵보기가 없는 군의 overt 홱보기 발생률과 covert 홱보기가 있는 군의 overt 홱보기 발생률을 Mann-Whitney $\mathrm{U}$ test를 통해 분석한 결과 covert 홱보기가 없는 군에서는 overt 홱보기의 발생률이 $81.9 \pm 28.5 \%$ 로 covert 홱보기가 있 는 군의 overt 홱보기 발생률 $47.2 \pm 40.5 \%$ 에 비해 높게 확인 되었으며 이는 통계학적으로 유의하였다 $(p<0.001)$ (Fig. 6).

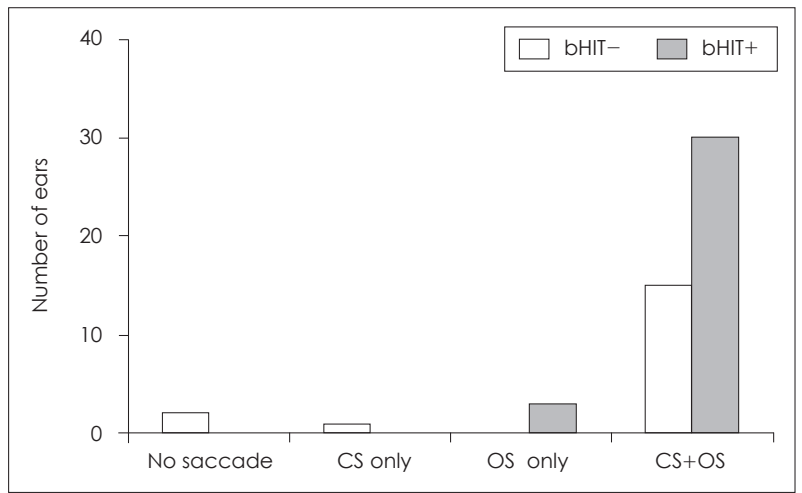

Fig. 4. The number of ears of bHIT negative group and bHIT positive group according to patterns of VHIT. CS: covert saccade, OS: overt saccade, bHIT: bedside head impulse test, vHIT: video head impulse test.

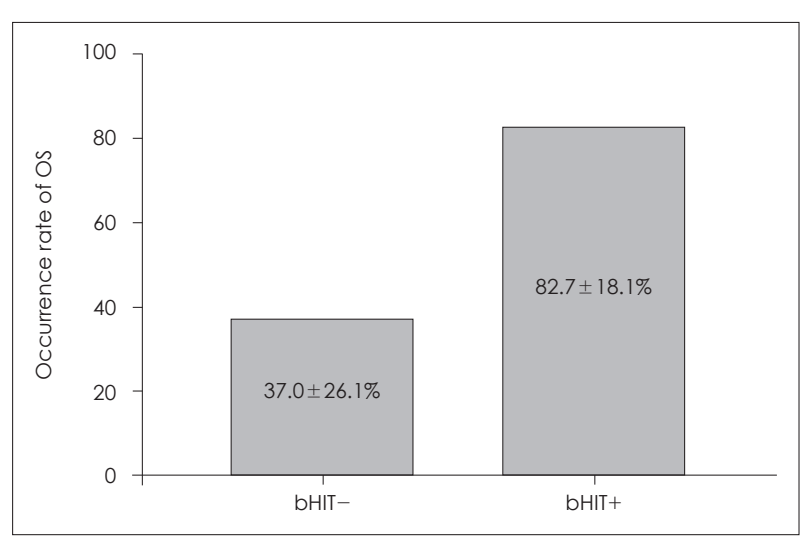

Fig. 5. Occurrence rate of OS between bHIT negative group and bHIT positive group. bHIT: bedside head impulse test, OS: overt saccade.

\section{고 찰}

두부충동검사는 전정안반사를 확인할 수 있는 검사의 일종 으로 Halmagyi와 Curthoys'에 의해 1988년 고안된 이래 전 정기능감소를 확인하기 위한 도구로 사용되고 있다. 최근에는 중추성 어지럼과 말초성 어지럼의 감별을 위한 도구로 주시 


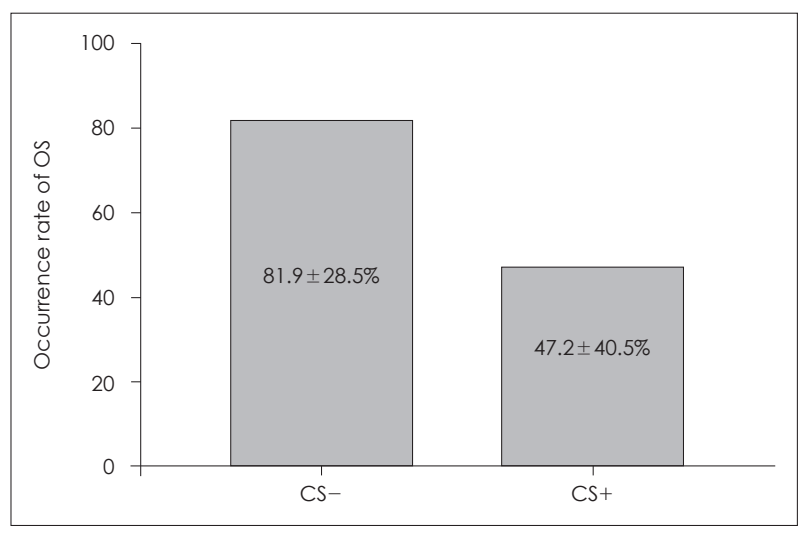

Fig. 6. Occurrence rate of OS between CS negative group and CS positive group. CS: covert saccade, OS: overt saccade.

유발안진(gaze-evoked nystagmus), skew 검사와 더불어 중 요한 검사로 알려져 있다. ${ }^{5}$ 두부충동검사는 나안으로 확인하 는 방법, 공막자기코일(scleral magnetic search coil)로 확인 하는 방법, 비디오 두부충동검사법 등이 있다. ${ }^{6}$ 특히 최근에 개발되어 사용되고 있는 비디오 두부충동검사는 저렴하며, 비 침습적이며, 간편하게 시행할 수 있으면서도 객관적인 결과를 기록할 수 있다는 장점이 있다. ${ }^{3)}$

나안 두부충동검사는 냉온교대 온도안진검사에 비해 낮은 민감도와 높은 특이도를 보인다는 점이 알려져 있는데, ${ }^{1)}$ 본 연구의 결과에 따르면 나안 두부충동검사 중 $35.3 \%$ 가 위음 성에 해당하는 것으로 나타났다. 저자들은 위음성의 원인을 분석하기 위해서 나안으로 검사를 시행하여 위음성이 발생 하는 경우들을 환자에게서 발생하는 홱보기의 유형에 따라 분류해 보았다. Fig. 4에서 나안 두부충동검사 시 음성인 경우 의 홱보기 유형을 참고해 보면 알 수 있는데, 먼저 전정안반사 의 이득은 감소되어 있으나 covert 홱보기와 overt 홱보기가 둘 다 나타나지 않는 위음성의 유형이 있다. 두 번째로는 overt 홱보기 없이 covert 홱보기만 나타나는 경우이다. 이 경우에는 covert 홱보기는 나타난다고 하더라도 두부운동과 중첩되어 나안으로는 확인이 어렵기 때문에 위음성으로 해석될 수 있 다. 마지막으로 overt 핵보기가 발생하지만 나안으로 관찰하 는 과정에서 홱보기를 놓치게 되는 경우이다. 본 연구에서는 총 48귀에서 overt 홱보기가 발생하였으며 이 중 15 귀(31.3\%) 에서 나안 두부충동검사 위음성 소견을 보였다.

Fig. 6에서 covert 홱보기가 발생하는 경우 overt 홱보기의 발생률이 떨어지는 것을 확인할 수 있는데 이는 교정성 핵보 기에서 covert 홱보기에 의해 일차적으로 보상이 이루어진 뒤 발생하는 overt 핵보기가 보상의 진폭이 작아 나안으로 는 이를 관찰하기 어려운 것일 가능성이 있다. 마찬가지로 Fig. 4에서 overt 홱보기 단독 발생이 아닌 overt와 covert 홱보기가 동시에 일어나는 군에서만 나안 두부충동검사 위음성이 나타
나는 것을 확인할 수 있다. 이 결과들을 종합해 보면 covert 홱보기의 발생은 overt 홱보기의 발생률을 낮춤으로써 나안 두부충동검사의 위음성에 있어 중요한 인자로 작용할 수 있 음을 알 수 있다.

나안 두부충동검사의 위음성을 줄이기 위한 노력으로는 먼저 적절한 두부 회전 속도의 유지가 필요하다. 비디오 두부 충동검사는 검사 중에 모니터를 통해 두부회전 속도를 확인 할 수 있어 적절한 회전 속도 유지가 용이하나 나안 검사 시에 는 적절한 두부회전 속도 유지가 어려울 수 있고 이로 인해 overt 홱보기가 나타나지 않아 위음성을 보일 수 있다. Weber 등ㄱㅇㅢ 보고에 따르면 빠른 가속도로 시행되는 나안 두부충 동검사의 경우 overt 홱보기가 더 크게 나타나 전정기능의 장애를 더 잘 파악할 수 있지만 이러한 경우 covert 홱보기 역시 더 자주 관찰된다고 하였다. 또한 환자가 두부충동검사 의 방향과 시기를 예측하게 되면 전정안반사의 이득이 증가 하여 교정성 핵보기의 잠복기가 짧아지고 covert 홱보기의 발생률이 증가할 수 있다. ${ }^{899}$ 결국 두부충동검사 시에 적절한 회전 속도를 유지하고 환자의 예측을 피하여 covert 홱보기 를 줄이기 위한 숙련이 필요하다.

본 연구는 나안 두부충동검사와 비디오 두부충동검사의 핵보기를 정성적인 방법으로 분석하여 결과를 해석하였다. 비디오 두부충동검사의 장점인 홱보기의 성질을 정량적으로 분석하여 결과를 해석한다면 보다 더 근본적인 원인을 분석 할 수 있을 것으로 사료된다. 이전 연구에서 일측성 전정기능 장애가 있는 환자에게 시행한 비디오 두부충동검사 결과 이 득의 감소와 함께 overt 및 covert 홱보기가 각각 단독으로 또는 동시에 나타나는 경우들에 대한 분석이 진행된 바 있 다." 그러나 이득의 감소가 있으면서 홱보기가 관찰되지 않는 환자군에 대한 연구는 아직 알려진 바가 없어 앞으로 이에 대 한 추가적인 연구가 필요할 것으로 보인다.

앞서 언급한 대로 현실적으로 비디오 두부충동검사를 시행 하기 어려운 일차 의료기관에서 어지럼 환자를 보는 경우에 중추성과 말초성의 감별을 위해 주로 나안 두부충동검사를 시행하게 되는데 항상 위음성의 가능성을 염두에 두고 그 원 인들로 앞서 언급한 부분들에 대한 이해가 필요하며 이를 줄 이기 위해 검사의 숙련도를 높이고 진단 시에는 다른 신경학 적 검사소견들을 종합적으로 고려해야 할 것으로 생각된다.

\section{Acknowledgments}

This research was supported by Basic Science Research Program through the National Research Foundation of Korea (NRF) funded by the Ministry of Science, ICT \& Future Planning (NRF-2016R1 C1B2014826). 


\section{REFERENCES}

1) Perez N, Rama-Lopez J. Head-impulse and caloric tests in patients with dizziness. Otol Neurotol 2003;24(6):913-7.

2) Yip CW, Glaser M, Frenzel C, Bayer O, Strupp M. Comparison of the bedside head-impulse test with the video head-impulse test in a clinical practice setting: a prospective study of 500 outpatients. Front Neurol 2016;7:58.

3) MacDougall HG, Weber KP, McGarvie LA, Halmagyi GM, Curthoys IS. The video head impulse test: diagnostic accuracy in peripheral vestibulopathy. Neurology 2009;73(14):1134-41.

4) Halmagyi GM, Curthoys IS. A clinical sign of canal paresis. Arch Neurol 1988;45(7):737-9.

5) Kattah JC, Talkad AV, Wang DZ, Hsieh YH, Newman-Toker DE. HINTS to diagnose stroke in the acute vestibular syndrome: threestep bedside oculomotor examination more sensitive than early
MRI diffusion-weighted imaging. Stroke 2009;40(11):3504-10.

6) Schmid-Priscoveanu A, Böhmer A, Obzina H, Straumann D. Caloric and search-coil head-impulse testing in patients after vestibular neuritis. J Assoc Res Otolaryngol 2001;2(1):72-8.

7) Weber KP, Aw ST, Todd MJ, McGarvie LA, Curthoys IS, Halmagyi GM. Head impulse test in unilateral vestibular loss: vestibulo-ocular reflex and catch-up saccades. Neurology 2008;70(6):454-63.

8) Lee SH, Newman-Toker DE, Zee DS, Schubert MC. Compensatory saccade differences between outward versus inward head impulses in chronic unilateral vestibular hypofunction. J Clin Neurosci 2014;21(10):1744-9.

9) Blödow A, Pannasch S, Walther LE. Detection of isolated covert saccades with the video head impulse test in peripheral vestibular disorders. Auris Nasus Larynx 2013;40(4):348-51. 